Eur J Clin Chem Clin Biochem

1995; 33:275-279

(c) 1995 Walter de Gruyter \& Co.

Berlin · New York

\title{
Identification of Apolipoproteins A-I and B Using High Resolution Electrophoresis on Supported Cellulose Acetate
}

\author{
By Soluzzo Cavalcanti ${ }^{1}$, Ernesta Cavalcanti ${ }^{2}$, Elvira Angotti ${ }^{2}$, Alessandra Liparoti $^{1}$ and Alfredo Colonna ${ }^{2}$ \\ 1 Laboratorio di Analisi Chimico Cliniche, I. N. R. C. A., Cosenza, Italy \\ ${ }^{2}$ Dipartimento di Medicina Sperimentale e Clinica, Facoltà di Medicina e Chirurgia, Catanzaro, Italy
}

(Received July 4, 1994/February 2, 1995)

Summary: A simple modification of high resolution electrophoresis on supported cellulose acetate is described. This modification is made by adding the surfactant Tween 20 to the buffer and permits the identification of apolipoproteins A-I and B as well as the usually detected serum proteins. The procedure is reproducible using various supported cellulose acetate plates with manual and automated procedures. Furthermore, this improved high resolution electrophoresis allows the semiquantitative evaluation of these apolipoproteins both on freshly collected and on $-20^{\circ} \mathrm{C}$ stored serum samples.

\section{Introduction}

High resolution electrophoresis on cellulose acetate is one of the most commonly used method for the detection of qualitative and/or quantitative abnormalities of serum proteins (1). The procedure is used to detect and evaluate prealbumin, albumin, $\alpha_{1}$-antiproteinase, $\alpha_{2}$ macroglobulin, haptoglobin, transferrin, $\mathrm{C} 3$ and immunoglobulins (2). However, experience with this well defined procedure has shown that of the serum proteins not detectable with this procedure, some are present in concentrations that are below the sensitivity of the method, while others such as $\alpha_{1}$-acid glycoprotein and lipoproteins, although present at elevated concentrations, are not detectable by high resolution electrophoresis since they demonstrate a low affinity for the more commonly used dyes or migrate as fuzzy bands $(3,4)$. Consequently, since high resolution electrophoresis on cellulose acetate does not adequately resolve the lipoproteins, other electrophoretic procedures are used to evaluate these serum components.

A previous study by Riches \& Kohn demonstrated that by the addition of Tween 20 to the buffer used to soak the cellulose acetate plates, the resolution is enhanced and two extra-bands are obtained, but they failed to characterized them (5). In this study, we describe a high resolution electrophoresis procedure modified by the addition of Tween 20 to the soaking and the migration buffer which allows the resolution of two well defined extra-bands that we have identified as apolipoprotein AI and apolipoprotein $\mathrm{B}$. The procedure does not alter the usual electrophoretic pattern and is also reliable for a semiquantitative evaluation of apolipoproteins A-I and B.

\section{Materials and Methods}

Samples

Random sera and plasma from healthy subjects and from patients of the School of Medicine, Catanzaro, and the National Institute of Recovery and Treatment for the Elderly (I.N.R.C.A.), Cosenza, Italy, were examined. Blood specimens were collected into vacutainer tubes (Becton Dickinson, Milan, Italy) and analyzed immediately. Aliquots of these serum samples were also stored at $+4{ }^{\circ} \mathrm{C}$ and $-20^{\circ} \mathrm{C}$

\section{Reagents and equipments}

Electrophoretic separation of samples was performed both manually and with an automatic system. For the manual procedure electrophoretic apparatus from Helena Laboratories (Beaumont, Texas) was used, and for the automatic procedure from Autopragma (Flow Group, Milan, Italy). 


\section{Plates}

Titan III and Titan III lipo supported cellulose acetate plates were used for the manual procedure (Helena Laboratories). Plates from Autopragma Flow Group were used for the automated method.

\section{Solutions}

\section{Buffer}

Tris barbital-sodium barbital, $0.04 \mathrm{~mol} / \mathrm{l}, \mathrm{pH} 8.8$ (Electra HR Buffer, Helena Laboratories, Beaumont, Texas) was used with the addition of $1 \mathrm{ml}$ of polyoxyethylene [20] sorbitan monolaurate (Tween 20) (Behring, Scoppito, Italy) to $1200 \mathrm{ml}$ of this buffer $(0.08 \% \mathrm{~V} / \mathrm{l}$, volume fraction 0.0008$)$. This buffer was used as soaking and running buffer.

\section{Staining solution}

Coomassie Brillant Blue (Aldrich, Milan, Italy), $5 \mathrm{~g} / 1$ in methanol/ acetic acid/distilled water $(4.5+1+4.5$ by vol. $)$.

\section{Destaining solution}

Methanol/acetic acid/distilled water $(4.5+1+4.5$ by vol.).

\section{Indicator solution!}

Bromophenol blue, $5 \mathrm{~g} / \mathrm{l}$ (Aldrich, Milan, Italy) in distilled water.

\section{High resolution electrophoresis procedure for the} estimation of lipoproteins

Two $\mu$ of serum samples were applied to the cathode side of the cellulose acetate electrophoretic plate that previously had been equilibrated in the buffer containing Tween 20 for 30 minutes when we used the manual technique. Electrophoresis was carried out at $260 \mathrm{~V}$ until the blue-stained albumin bánd migrated to $3.5 \mathrm{~cm}$ (about 30 minutes). After migration, the plate was transferred first to the staining solution for 15 minutes and then to the destaining solution. The destained plate was dried with cold forced air until completely dry. For the automatic procedure, high resolution electrophoresis was carried out in the same running buffer containing Tween 20 at $350 \mathrm{~V}, 14 \mathrm{~mA} /$ plate for 20 minutes.

\section{Immunofixation electrophoresis}

Two $\mu$ l of serum samples were applied to the cathode side of a supported cellulose acetate plate (Flow Group) that was previously soaked for 30 minutes in the Electra HR buffer with or without Tween 20, depending on the experiments. After electrophoresis, performed under the same experimental condition described above, a sandwich with a substrate plate layered with anti apolipoprotein A-I and apolipoprotein B antisera (OUED and OSAN, respectively, Behring) was prepared. Immunofixation (immunoprecipitate formation) was completed after an incubation at $37^{\circ} \mathrm{C}$ for 30 minutes. The plate used for migration was then rinsed twice in saline solution $(\mathrm{NaCl} 9 \mathrm{~g} / \mathrm{l})$ for 30 minutes, stained with Brillant Coomassie Blue for 15 minutes, destained and dried at $56^{\circ} \mathrm{C}$ for 5 minutes.

\section{Immunosubtraction}

The immunosubtraction technique was performed according to Merlini et al. (6) using anti apolipoprotein A-I and anti-apolipoprotein B antisera.

\section{Serum lipoprotein precipitation}

Sodium phosphotungstate and $\mathrm{MgCl}_{2}$ were used as precipitant agents for low density lipoproteins (LDL) and very low density lipoproteins (VLDL) $(7,8)$. Polyvinylsulphate precipitation according to Assmann et al. (9) was used for LDL. After precipitation, supernatants were collected and used for electrophoresis.

\section{Quantitative determination of serum lipids}

Total serum cholesterol was measured by, an enzymatic colorimetric method on an automatic analyzer (Monarch 2000 - Instrumentation Laboratory, Milan, Italy). High density lipoprotein (HDL), cholesterol was determined using the same method after precipitation of LDL and VLDL fractions by polyethylene glycol 6000 . All reagents were obtained from Instrumentation Laboratory. Apolipoproteins A-I and B were measured by immunonephelometric assay. The determinations were performed on an automatic nephelometer (Behring Nephelometer Analyzer). Quality control assessment was performed daily for all determinations. Interlaboratory quality control was performed according to QCS from Boehringer Mannheim. Between batch imprecision (CV\%), over 54 days, was $3.4 \%$ $(x=2.3 \mathrm{mmol} / \mathrm{l})$ for total cholesterol, and $6.7 \%(x=1.3 \mathrm{mmol} / \mathrm{l})$ for HDL cholesterol. For apolipoproteins $A-I$ and $B, C V$ values were $13.1 \%(x=1.58 \mathrm{~g} / \mathrm{l})$ and $13.3 \%(\mathrm{x}=1.14 \mathrm{~g} / \mathrm{l})$, respectively.

\section{Results}

\section{Improved high resolution electrophoresis} procedure

The electrophoretic separation of plasma samples was performed with addition of the surfactant Tween 20 to the buffer (fig. 1). Two additional bands were revealed with this modified procedure: one in the $\alpha_{2}$-zone and another in the $\beta$-zone. Importantly, the addition of Tween 20 to the buffer did not affect the usual electrophoretic pattern of plasma proteins. Typical high resolution electrophoresis patterns were in fact obtained with samples from healthy subjects (lanes 1,3 to 13,15 to 23), from a subject with a monoclonal component in $\gamma$ zone (lane 2), and in a sample in which the $\alpha_{1}$-antiproteinase, haptoglobin and fibrinogen are moderately increased (lane 14).

We verified that these results are also reproducible using other kinds of supported media, such as a supported cellulose acetate that is usually adopted for serum lipoprotein electrophoresis (Titan III Lipo from Helena Laboratories).

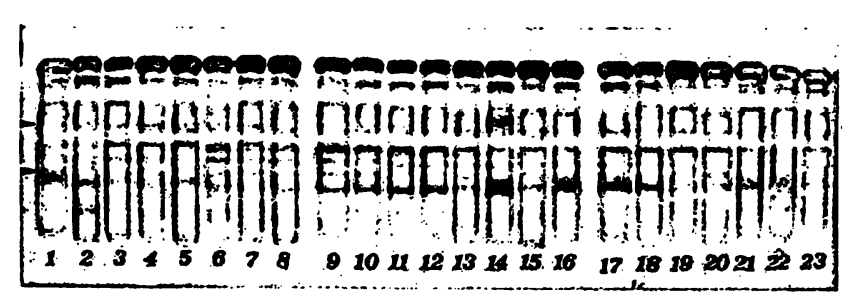

Fig. 1 High resolution electrophoresis of plasma samples. Results were obtained on an automatic device using running buffer containing $1 \mathrm{ml}$ of Tween 20 in $1200 \mathrm{ml}$. The arrows indicate the extra bands in the $\alpha_{2}$ - and $\beta$-zones. 
Nature of the additional bands and their characterization

The serum proteins that constitute the two additional bands were identified by immunofixation electrophoresis performed with anti-apolipoprotein A-I and antiapolipoprotein B antibody adding Tween 20 to the buffer.

Figure 2 shows the immunofixation electrophoresis of three patients' sera performed with anti-apolipoprotein $B$ antisera (both migration and immunofixation electrophoresis were performed in the presence of Tween 20). This experiment demonstrated that the apolipoprotein B migrates at the same level of the extra-band in the $\beta$ zone.

When sera samples were treated with chemicals known to cause LDL precipitation (polyvinylsulphate), or precipitation of the LDL and VLDL fractions (phosphotungstic acid and magnesium chloride), this extra-band no longer appeared in the electrophoretic pattern (fig. 3). This confirms that the extra-band corresponds to the apolipoprotein B and excludes that other proteins eventually comigrating with apolipoprotein B may be responsible for the extra band.

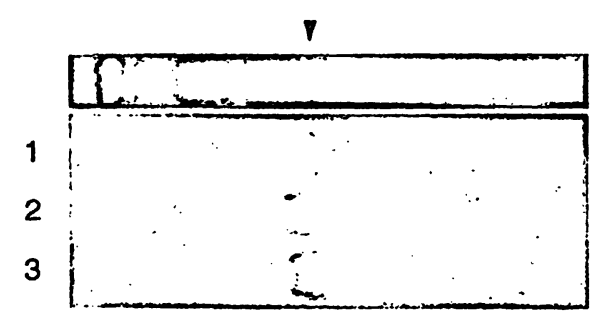

Fig. 2 Immunofixation electrophoresis of the sera of three patients treated with anti-apolipoprotein B antibody. The arrow indicates the extra band in the $\beta$-zone. The electrophoretic separation and immunofixation procedures were performed using buffer containing Tween 20 .

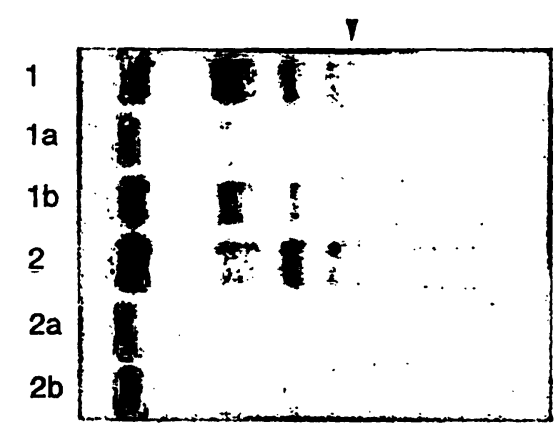

Fig. 3 Effect on the electrophoretic pattern by the pretreatment of sera with polyvinylsulphate $(1 \mathrm{a}, 2)$ and phosphotungstic acid + magnesium chloride $(1 b, 2 b)$; native serum $(1,2)$. The arrows indicate the position of the extra band in the $\beta$-zone. This extra band did not appear when the sera were pretreated.

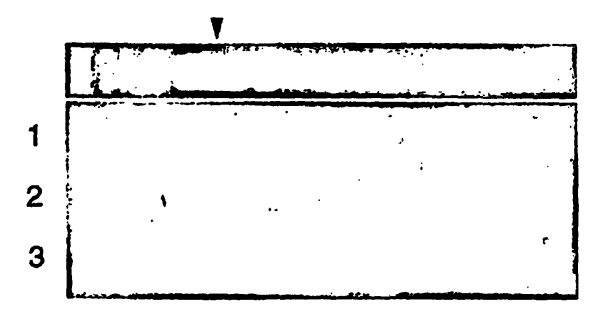

Fig. 4 Immunofixation electrophoresis of three patient sera treated with anti-apolipoprotein A-I antibody. The arrow indicates the extra band in the $\alpha_{2}$-zone.

Immunofixation electrophoresis performed with antiapolipoprotein A-I antiserum (in this case the experiments were also performed in presence of Tween 20), showed that the extra band in the $\alpha_{2}$-zone corresponded to the apolipoprotein A-I (fig. 4). The patient sera were previously depleted of LDL using polyvinylsulphate in order to minimize cross reactions. We observed two bands: a major one in the $\alpha_{2}$-zone and a minor one in $\beta$-zone. This minor band might be due to cross-reaction with residual $\beta$-lipoprotein. As a control of specificity, an immunosubtraction electrophoresis with anti-apolipoprotein A-I and anti-apolipoprotein B antisera were performed. The disappearance of the extra-bands was a further confirmation of the nature of the additional bands as apolipoproteins A-I and B (data not shown).

Comparison of high resolution

electrophoresis results versus total

cholesterol and apolipoprotein B quantitative determinations

To verify that this modified technique could be used for the semiquantitative evaluation of the apolipoproteins A-I and B, sera from 110 random subjects were analyzed for total cholesterol, HDL cholesterol, apolipoproteins A-I and B. In addition, we performed high resolution electrophoresis in the presence of Tween 20 using the manual procedure and the Titan III lipo plates. The evaluation was performed by visual inspection of the plate, following the suggestion to disuse the densitometric quantification of the proteins separated by means of high resolution electrophoresis (10). The intensity of the apolipoprotein B band from serum samples was compared with control serum with a known level of cholesterol and apolipoprotein B. The results were expressed using an arbitrary scale of values: normal, slightly, moderately and very increased or diminished.

As shown in table 1, there was a good correlation between the quantitative assay of cholesterol and apolipoprotein B and the evaluation of apolipoprotein B by visual inspection of high resolution electrophoresis pat- 
Tab. 1 Visual evaluation of high resolution electrophoresis pattern versus quantitative assay of Jotal cholesterol and apolipoprotein B

\begin{tabular}{llll}
\hline $\mathrm{N}$ & $\begin{array}{l}\text { High } \\
\text { resolution } \\
\text { electrophoresis (a) }\end{array}$ & $\begin{array}{l}\text { Cholesterol } \\
(\mathrm{mmol} / \mathrm{l})(\mathrm{b}) \\
(\overline{\mathrm{x}}+\mathrm{SD})\end{array}$ & $\begin{array}{l}\text { Apolipo- } \\
\text { protein B } \\
(\mathrm{g} / \mathrm{l})(\mathrm{c}) \\
(\overline{\mathrm{x}}+\mathrm{SD})\end{array}$ \\
\hline 1 & +++ & 8.2 & 1.93 \\
14 & ++ & $6.9 \pm 0.3$ & $1.72 \pm 0.2$ \\
12 & + & $6.1 \pm 0.1$ & $1.52 \pm 0.1$ \\
80 & Normal & $4.9 \pm 0.6$ & $1.15 \pm 0.2$ \\
3 & - & $3.1 \pm 0.1$ & $0.60 \pm 0.1$ \\
\hline
\end{tabular}
(a) $+++=$ very increased
$++=$ moderately increased
$+=$ slightly increased
$-=$ slightly diminished

(b) reference values: $(3.6-5.6 \mathrm{mmol} / \mathrm{l})$

(c) reference values: $(0.56-1.49 \mathrm{~g} / \mathrm{l} ; 0.59-1.54 \mathrm{~g} / \mathrm{l})$

terns. This finding confirmed the validity of our modified procedure.

The same evaluation was not performed for apolipoprotein A-I because no serum samples had very low levels of HDL cholesterol. Moreover, our study confirms that apolipoprotein A-I diminished during acute inflammation (see fig. 1, lane 14).

To verify the stability of apolipoproteins, we aliquoted eight different fresh collected sera samples. One set was stored at $4{ }^{\circ} \mathrm{C}$ and an other at $-20^{\circ} \mathrm{C}$. Serum samples stored at $4{ }^{\circ} \mathrm{C}$ were analyzed, with the manual technique, for ten days consecutively. The samples stored at $-20^{\circ} \mathrm{C}$ were analyzed at four, ten, fifteen and thirty days from the collection. No differences in the electrophoretic pattern were observed in any of the stored samples.

\section{Discussion and Conclusion}

Over the last decade, plasma protein data have been increasingly used to aid in the diagnosis of various diseases and provide pathophysiological information (11).
High resolution electrophoresis of serum proteins on agarose gel at high voltage allows the detection and evaluation of at least eleven proteins (prealbumin, albumin, $\alpha$-lipoprotein, $\alpha_{1}$-antiproteinase, $\alpha_{1}$-antichymotrypsin group, $\alpha_{2}$-macroglobulin, haptoglobin, haemopexin, transferrin, $\beta$-lipoprotein, C3 and immunoglobulins) (5) but this procedure is expensive, and requires carefull handling of the gels. High resolution electrophoresis on supported cellulose acetate plates, the procedure most widely used to determine serum proteins, fails to detect lipoproteins even though they are present in high concentrations. With the addition of a non-ionic detergent (Tween 20) to the soaking and running buffer, we obtained an electrophoretic pattern in which, besides the normally detected serum proteins, two well defined extra-bands corresponding to apolipoproteins A-I and B were resolved. This finding is probably due to the interaction between Tween 20 and the lipidic components of the lipoproteins and the supported cellulose acetate. As a consequence of the detergent addition, apolipoprotein A-I, which generally migrates as a fuzzy band, forms a more sharp band in $\alpha_{2}$-zone. On the other hand, the apolipoprotein $\mathrm{B}$ migrates at a slightly more cathodic position and consequently appears better separated from the $\mathrm{C} 3$ band.

Moreover, on the basis of the correlation between the intensity of these bands and their serum concentration, early clinical information is obtained that might be used to address the quantitative determination of the apolipoproteins.

The modified procedure described here is reproducible, simple and allows the semiquantitative evaluation of the apolipoproteins A-I and B as well as of other serum proteins. Therefore, significantly more information can be obtained from the electrophoresis of serum proteins with this simple modification.

\section{Acknowledgements}

We are grateful to Prof. Francesco Salvatore for giving us the benefit of his experience.

\section{References}

1. Sun T, Lien YY, Gross S. Clinical application of high resolution electrophoresis system. Ann Clin Lab Sci 1978; 8:21927.

2. Wolf PL, editor. Clinics in laboratory medicine. Electrophoresis of serum proteins and isoenzymes. Philadelphia: Saunders Co, 1986.

3. Aufenanger J, Haux P, Kattermann R. Improved method for enzymic determination of cholesterol in lipoproteins separated by electrophoresis on thin layer agarose gels. J Clin Chem Clin Biochem 1989; 27:807-13.

4. Jeppson JO, Laurell CB, Franzen B. Agarose gel electrophoresis. Clin Chem 1979; 25:629-38.

5. Riches PG, Kohn J. Improved resolution of cellulose acetate membrane electrophoresis. Ann Clin Biochem 1987; 24:77-9.

6. Merlini G, Pavesi F, Carini A, Zorzoli I, Valentini O, Aguzzi F. Identification of specific plasma proteins determining the agarose gel electrophoresis by the immunosubstraction technique. J Clin Chem Clin Biochem 1983; 21:841-4.

7. Burstein M, Scholnich HR, Morfin R. Rapid method for the isolation of lipoproteins from human serum by precipitation with polyanions. J Lipid Res 1970; 11:583-95.

8. Lopes-Virella MF, Stone P, Ellis S, Colwell JA. Cholesterol determination in high-density lipoproteins separated by three different methods. Clin Chem 1977; 23:882-4. 
9. Assmann G, Jabs HU, Kohnert U, Nolte W, Schriewer H. LDL cholesterol determination in blood serum following precipitation of LDL with polyvinylsulfate. Clin Chim Acta 1984; 140:77-83.

10. Aguzzi F, Jayakar SO, Merlini G, Petrini C. Electrophoresis: cellulose acetate vs agarose gel, visual inspection vs densitometry. Clin Chem 1981; 27:1944-5.
11. Killingsworth LM. Plasma protein patterns in health and disease. CRC critical review in Clinical Laboratory Sciences. 1979; 11:1-30.

Prof. Alfredo Colonna

Dipartimento di Medicina Sperimentale e Clinica

Facoltà di Medicina e Chirurgia

Via T. Campanella

I-88100 Catanzaro

Italy 


$$
\text { . }
$$

